Fecha de recepción: mayo 2020 Fecha de aceptación: junio 2020 Versión final: julio 2020

\section{Indumentaria indígena: ética, política y diseño. Una mirada sobre el artefacto vestimentario de la mujer chibuleo}

Resumen: La indumentaria, como artefacto de diseño portado por las mujeres indígenas durante la década de 1990, tiene inscripciones políticas que transforman el cuerpo social de estas mujeres en un cuerpo político, que denuncia opresiones y demanda derechos. En este sentido, se analiza la vestimenta, por una parte, en tanto interfaz que comunica la lucha por la reivindicación de los derechos de la etnia. Por la otra, como prótesis que amplía las capacidades del cuerpo para ocupar el espacio público, durante los levantamientos indígenas acontecidos en Ecuador en la década de 1990.

Esa época fue decisiva respecto de la representatividad indígena en la política ecuatoriana; proceso similar al que se producía en otros países de Latinoamérica. Los levantamientos y la consolidación del movimiento social indígena, registran la importancia de este grupo en la historia de la construcción del Estado-Nación. Las acciones tomadas por esta minoría étnica, decantan en el reconocimiento constitucional de sus derechos en la Carta Magna de 1998. En este escenario, las mujeres indígenas inscriben su presencia a través de la indumentaria, que portan tanto en la esfera pública como privada. La vestimenta identifica el pueblo de pertenencia de las mujeres; asimismo dota a estas personas de una identidad colectiva que se fortalece en el uso cotidiano del artefacto de diseño.

La identidad se resignifica en concomitancia con la indumentaria. El cuerpo vestido de las mujeres chibuleo, que en un primer momento pone en evidencia su trabajo rural en la comunidad, se transforma en un cuerpo político, cuya vestimenta visibiliza a las mujeres en el espacio público urbano, y con ello, la existencia del pueblo mismo en el marco de la lucha y demanda de derechos de los pueblos y nacionalidades indígenas en Ecuador. La indumentaria se constituye en el artefacto de diseño con impronta política, que representa la identidad resignificada del pueblo en particular y de las minorías étnicas en general.

Palabras clave: Indumentaria - mujer indígena - identidad - política - artefacto de diseño

[Resúmenes en inglés y portugués en las páginas 40-41]

${ }^{(*)}$ Doctora en Diseño (Facultad de Diseño y Comunicación, Universidad de Palermo, Argentina). Ingeniera en Diseño de Modas (Universidad Cristiana Latinoamericana, Ecuador). Mg. en Docencia y Currículo para la Educación Superior (Universidad Técnica de Ambato, Ecuador). Cargo actual: Profesora Titular e Investigadora (Universidad Técnica de Ambato Ecuador). aylenkmedina@uta.edu.ec 


\section{Introducción}

El presente artículo analiza a la indumentaria como artefacto de diseño; las múltiples formas en que este objeto vestimentario, usado por las mujeres indígenas, comunica la identidad de un pueblo en el proceso de reconocimiento identitario, y amplía sus capacidades materiales y culturales, tanto para adaptarse al entorno de uso como para desenvolverse en la trama de la que es parte.

La indumentaria identifica a la etnia al tiempo que la diferencia de los no indígenas; este artefacto de diseño fue dotado de sentido e identidad durante los denominados levantamientos nacionales, en la década de 1990. En el siglo XX — particularmente desde la década del 70-, en toda Latinoamérica los indígenas se ven envueltos en una serie de eventos enmarcados por represiones sociales y políticas de las etnias, en los que se protesta y demanda - a los no indígenas - la reivindicación de sus derechos y su inclusión en el Estado-Nación (Jackson, 1995; Ulloa, 2005), como en el caso de los pueblos originarios del Chaco argentino (Spadafora, Gómez y Matarrese, 2010) que reclaman sus territorios y exigen reformas constitucionales conducentes al cumplimiento de los derechos de los pueblos indígenas. Sin embargo, es hasta inicios de 1990 que la etnia chibuleo adquiere atención por parte del Estado-Nación en Ecuador, que hasta ese entonces no reconocía su representatividad y menos aún los registraba como actores de la sociedad ecuatoriana, por lo que sobrevino un ciclo de negociaciones entre ambos.

Dentro de la década de 1990 - en la que se desarrolla la trama indumentaria de las mujeres chibuleo que se expone en el presente artículo-, confluyen las transformaciones sociopolíticas de la etnia en el Ecuador, con un proceso de revitalización vestimentaria que da cuenta de estos procesos.

Los indígenas se autorrepresentan a través de la vestimenta en una continua negociación (Wright, 1998; Jackson, 1995) entre una etnicidad privada que se vuelve pública en los levantamientos nacionales, y que continúa hasta la actualidad en los chibuleo. Entre estos movimientos, el más decisivo es el acaecido en junio de 1990 en Ecuador, seguido de los ocurridos en 1992 y 1994. Eventos que continúan hasta finales del siglo XX e inicios del $\mathrm{XXI}$, con los que los indígenas no solo alcanzan el reconocimiento de su existencia y derechos, sino que logran una representatividad política que los coloca en la primera línea de actores que hacen prevalecer sus derechos y también los de los no indígenas con menores recursos económicos.

El abordaje propuesto, respecto al diseño de la indumentaria como el lugar de las inscripciones políticas chibuleo, no ha sido analizado ampliamente; solo los estudios de Medina (2019) hacen una investigación al respecto. Existen otros escritos, que aun cuando no refieren a la etnia que es motivo de este estudio, ni hacen referencia al diseño indumentario, destacan el importante rol desempeñado por las mujeres indígenas y su consecuente participación en la política ecuatoriana, con sus cuerpos ataviados con vestimenta indígena, como un acto de denuncia y demanda de lo diferente, como explico a continuación. Los estudios de Medina (2019), a partir de los que se desarrolla el presente artículo, constituyen el referente principal para el abordaje del artefacto vestimentario de las mujeres chibuleo con inscripciones políticas durante la década de los años 90 . Anterior a este análisis, 
se encuentran los estudios de autores como Rowe $(1998,2011)$ y Caluña et al. (2008), que si bien no articulan directamente indumentaria y política, son referentes indispensables. La primera autora da cuenta de la indumentaria portada en tiempos previos a los levantamientos indígenas, a partir de su etnografía en 1988 en Ecuador, con una perspectiva histórica-antropológica; mientras que el segundo autor describe la historia de su pueblo de pertenencia, en la que se entreteje la indumentaria como una de las particularidades y costumbres chibuleo.

Por la otra, los estudios que contribuyen de manera específica a los roles que asumen las mujeres kichwas en Ecuador, portadoras del vestido étnico ${ }^{1}$ (Eicher, 2000; Hansen, 2004) como una estrategia de posicionamiento público-político durante las revueltas de 1990, y en los nuevos roles que asume la mujer como resultado de la lucha indígena, con autores como De la Torre (2010); Prieto, Cuminao, Flores, Maldonado y Pequeño (2005), y Pequeño (2007).

En su escrito, De la Torre (2010) hace referencia a la indumentaria que visibiliza los cuerpos indígenas de las mujeres y aportan al cambio histórico de la etnia. Prieto et al. (2005) hace notar que en la construcción del respeto de la etnia, concomitantemente se construye el respeto de las mujeres indígenas al interior de la etnia y con respecto a los no indígenas; la vestimenta se convierte en un "vehículo de 'identidad étnica" (p. 164).

Pequeño (2007) evidencia la relación entre indumentaria e identidad, que reafirma la pertenencia étnica de las mujeres indígenas. Sus cuerpos vestidos se convierten en territorios culturales y políticos de autoidentificación, que lejos de continuar siendo catalogados como un "rasgo de retraso" (p. 111) por parte de los no indígenas, trascienden para contextualizar los nuevos roles que asumen las mujeres como dirigentes y lideresas.

Además, se incluyen los estudios identitarios de mujeres indígenas a nivel latinoamericano, con autores como De la Cadena (1991) respecto a las comunidades de Cusco en Perú, y los de Rodríguez Maeso (2008) que incorpora estudios en Ecuador, Perú, Guatemala y México. De la Cadena (1991) explora las relaciones entre hombres y mujeres a nivel intraétnico e interétnico. Esta autora explica, por una parte, el rol subordinado de la mujer, a la que no se le reconoce el trabajo que realiza en el hogar, dado que no está considerado como trabajo - ni remunerado ni no remunerado-, en tanto se lo considera propio del género. Por la otra, expone las alianzas entre indígenas y no indígenas, que generan mayor poder al unir sus tierras.

Rodríguez Maeso (2008) estudia los procesos de identificación indígena en los contextos latinoamericanos, la manera en que las relaciones de poder asimétricas cincelan los nexos entre género e identidad, y la constitución de las mujeres como sujetos políticos que intervienen "sobre la exterioridad de la representación" (p. 67), que puede ser interpretada a través del vestido.

Habida cuenta de lo expuesto, si bien estos estudios abordan la trascendencia de la indumentaria de las mujeres indígenas desde la década de 1990 en adelante, no se explora detalladamente su potencialidad como artefacto de diseño con impronta política, ni su aporte en la visibilización de la etnia, ni tampoco como extensor de las capacidades de las mujeres para llevar adelante estas acciones, por lo que constituye una vacancia investigativa. 
Por esta razón, con el presente documento se pretende contribuir en el estudio de la indumentaria como artefacto de diseño, analizado desde la etnia indígena. Por un lado, como la interfaz que al comunicar la lucha indígena por la reivindicación de sus derechos da cuenta de las inscripciones políticas del artefacto vestimentario. Por el otro, como prótesis cultural que acompaña estos procesos, utilizada para maximizar las potencialidades físicas de las mujeres.

Para ello, se desarrolla aquí una mirada histórico-política de los levantamientos, las demandas indígenas y los resultados obtenidos, como primer punto; se continúa con una puesta en escena de la mujer y su indumentaria como estrategia identitaria; por último, se explica el modo en que la indumentaria tiene inscripciones políticas en tanto artefacto del diseño.

\section{Los levantamientos, breve cronología de una transformación identitaria}

Los levantamientos de la década de 1990 inician en el mes de junio ${ }^{2}$ de ese año. Ese evento, que tuvo como principal demanda el reconocimiento del Estado ecuatoriano como plurinacional (Benítez y Garcés, 2014), marca el inicio de una transformación identitaria étnica en el país, en la que se reafirma la identidad indígena. Asimismo, pone en evidencia el protagonismo político alcanzado por las organizaciones indígenas (Benítez y Garcés, 2014), y la importancia de la Confederación de las Nacionalidades Indígenas del Ecuador (CONAIE) como principal impulsora del levantamiento, bajo la consigna de cambiar la visión de la sociedad respecto al indígena (Cruz, 2010).

Este levantamiento hace públicas las demandas mencionadas en el programa "Mandato por la Defensa de la Vida y las Nacionalidades Indígenas" (Almeida, Arrobo, y Ojeda, 2005), en el que los pueblos solicitan que se resuelvan sus conflictos de tierras y se implemente como un derecho la educación intercultural bilingüe (Almeida et al., 1992; Porras, 2005). Además, en un hecho sin precedentes, se cuestiona que la carta constitucional haga caso omiso respecto de la plurinacionalidad del Estado.

Este evento es producto de la reacción indígena en relación con una histórica exclusión de la etnia en el Estado-Nación, y de la conculcación de derechos sufrida durante siglos. A través de este levantamiento, los pueblos indígenas se sitúan en el escenario político ecuatoriano como "sujetos sociales y actores políticos" (Iturralde, 2000, p. 24), y la CONAIE se consolida como un actor político capaz de representar a la etnia, plantear propuestas de transformación, negociar e intervenir en la institucionalidad pública y la legislación. Así también queda evidenciada la necesidad de reconocer las prácticas culturales de las identidades étnicas en el Estado-Nación — habitado por varios pueblos y nacionalidades-, y reestructurar el régimen democrático no solo con la reivindicación de los derechos de la etnia, sino también con la participación política indígena.

En Tungurahua, provincia en la que residen los chibuleo ${ }^{3}$, este evento se vivió -al igual que los siguientes de 1992 y 1994 -, con la ocupación del espacio público urbano de Ambato, la paralización de esta ciudad y el cierre de los mercados. Las mujeres, portadoras de la "vestimenta propia"" (Medina, 2019), fueron la estrategia de entrada a la ciudad, al abrir 
paso a su grupo étnico derribando a la fuerza policial y militar que intentaba reprimir este acto. El levantamiento de 1990 le puso en evidencia a los propios chibuleo, la importancia de vestir con la indumentaria étnica, en tanto solo fueron reconocidos - e incluso obtuvieron apoyo de los no indígenas - quienes vestían indumentaria indígena.

Con el antecedente del levantamiento de 1990, se suscita otro en octubre de 1992, en repudio a la memoria de los "500 años del descubrimiento de América" (Benítez y Garcés, 2014, p. 269). En esta ocasión también destaca la participación de la mujer indígena, en los mismos términos que en el primer levantamiento de la década. La movilización puso en evidencia la discriminación y explotación que los indígenas han sufrido desde la época de la conquista, ligadas ahora a las políticas de ajuste económico (Tello, 2012) que afectaban a la población desde una década atrás.

Al igual que en 1990, la etnia demanda justicia y equidad. Frente a los paupérrimos ofrecimientos de las autoridades de turno - orientados a regalar víveres para la subsistencia indígena-, el grupo se indigna y plantea que el problema radica en la obtención de justicia. Como resultado de estos eventos, y pese a las disconformidades entre las partes, se firman acuerdos; los indígenas - en particular los chibuleo - consolidan la idea de vestir sus atuendos en contribución a su reafirmación identitaria. Para esta época, la importante participación que tienen las mujeres desde inicios de los 90, decanta en organizaciones lideradas por ellas mismas, visibilizándolas tanto en sus relaciones intraétnicas como interétnicas.

En el levantamiento de junio del año 1994, los indígenas exigen la derogación de la Reforma de la Ley de Desarrollo Agrario, creada - al igual que en otros países latinoamericanos-, en el marco de la implementación de medidas neoliberales. Como consecuencia de estas movilizaciones, se archiva la referida ley, que beneficiaba la explotación empresarial y la disolución de las tierras comunales (Benítez y Garcés, 2014). Más allá de ello, por una parte, los indígenas avanzan en el reconocimiento de territorios y concesión de títulos de propiedad (Tello, 2012), que estaban demandando desde 1990. Por la otra, la CONAIE pone en evidencia la representatividad indígena en la esfera pública.

Esta reafirmación pública requirió de marcadores étnicos, no solo del grupo indígena en general, sino de los líderes y lideresas en particular (Pequeño, 2007), a partir de diacríticos como la indumentaria - cuya importancia había sido identificada desde 1990- y el idioma. En este levantamiento, registrado por los chibuleo como una "movilización nacional por la vida, en la que más allá de la derogatoria de una ley, se exigía el respeto de los derechos indígenas" (Medina, 2019, p. 113), la indumentaria utilizada constituye "una declaración pública de su identidad" (p. 113). Evento que en Tungurahua se vivió con características similares a los levantamientos que le anteceden - paralización de las ciudades y desabastecimiento de productos alimenticios-.

Habida cuenta de lo expuesto, los tres levantamientos descriptos articularon la demanda de justicia y respeto de la etnia, como también al reconocimiento de sus territorios e identidad. Asimismo, por un lado, marcan el inicio de una revitalización indumentaria como diacrítico identitario, que autoidentifica a los indígenas y los diferencia de los no indígenas. Por el otro, posiciona a las mujeres como seres capaces de liderar masas y de convertirse en ejes estratégicos en la lucha indígena - al encabezar las manifestaciones como puertas de entrada del grupo étnico a las ciudades-, y de visibilizar la presencia étnica con sus cuerpos vestidos ocupando el espacio urbano. 
Estos tres levantamientos son los registrados como los de mayor relevancia por los chibuleo, en tanto — según indican - consiguieron “¡el gran respeto!” (Entrevista con TJJLL Chibuleo San Francisco, mayo de 2016). A partir de estas movilizaciones, según sostienen los chibuleo, "desde ahí ha cambiado por completo, hasta ahí siii nuestras espositas eran burladas [...] Pero ahora sí gracias a nuestra lucha, gracias a nuestro levantamiento, gracias a nuestra unidad, ahora sí cambió" (Entrevista con TJJLL, Chibuleo San Francisco, abril de 2016).

Más aún, su importancia aumenta con el reconocimiento constitucional de los derechos de los pueblos indígenas, plasmados en la Carta Magna de 1998, documento que en su artículo 84 plantea el fortalecimiento de la identidad indígena, y el uso de símbolos y emblemas que los identifiquen, entre los que se encuentra la vestimenta. Este abordaje es sobrepasado posteriormente por la Constitución de 2008, que en el artículo 57 incluye directamente el término 'vestimenta' como un derecho colectivo de las comunidades, pueblos y nacionalidades del Ecuador, y menciona el impulso del uso de esta para la identificación de sus portadores.

Luego de estos eventos, el movimiento indígena nacional accede a la agenda gubernamental. A partir de sus demandas, alcanzan la implementación de la educación bilingüe; la participación del grupo étnico en espacios educativos superiores (Almeida et al., 1992; Porras, 2005) y en puestos de trabajo tanto públicos como privados. Asimismo, los indígenas se posicionan como dirigentes políticos nacionales en sus propios términos, es decir, sin la necesidad de adoptar la indumentaria, el discurso y las costumbres de un dirigente no indígena. Este hecho constituye un importante cambio de paradigma, ya que hasta ese entonces había sido prácticamente obligatorio para acceder a una carrera de esa naturaleza. En adelante, los dirigentes indígenas, principalmente, y el grupo étnico, son portadores de la vestimenta de su procedencia, siendo respetados en sus prácticas y costumbres.

Los levantamientos expuestos, culminan con marchas pacíficas en la ciudad de Ambato; la vestimenta propia, portada por los indígenas, ocupa la urbe y pone en evidencia su representatividad en Ambato, Tungurahua y el resto del país.

\section{La mujer indígena y su indumentaria como estrategia identitaria}

La participación de las mujeres indígenas, con su intervención estratégica, constituyó uno de los ejes primordiales - y así lo entendieron los chibuleo- del éxito de los levantamientos. Es a través de sus cuerpos vestidos que marcan la presencia étnica a nivel local y nacional en el espacio público, visibilizándolos, y aportando al reconocimiento indígena en el Estado-Nación, como sujetos políticos.

De acuerdo a la etnografía de Medina (2019), si bien los "taytas"5 fueron la voz chibuleo, el rol que cumplen las mujeres en estos eventos fue fundamental, aseveración sostenida a partir de lo expuesto por los taytas: "en el levantamiento del año 90 ah nuestras esposas tuvieron un papel demasiado fuerte, demasiado" (Entrevista con TJJLL, Chibuleo San Francisco, abril de 2016). Cabe aclarar en este punto que las esposas de los taytas - presentes en estos eventos y activistas - adquieren la categoría nativa de "mamas". 
Durante los levantamientos de la década de 1990, las calles urbanas se vieron desbordadas de anacos sostenidos por chumbis, rebozos entrelazados con tupus, camisas con bordados, sombreros blancos, wallkas y orejeras, portados en los cuerpos de las mujeres indígenas que reclamaban justicia y respeto (Medina, 2019). Un hecho que también registra De la Torre (2010) a nivel nacional, refiriéndose al anaco portado por las mujeres kichwas andinas como "un acto político de denuncia y demanda" (p. 3). En este escenario portar la vestimenta indígena, es "una estrategia de autoidentificación, un acto político que denuncia la invisibilización del grupo étnico por parte del Estado-Nación y de la sociedad ecuatoriana" (Medina, 2019, p. 115).

En efecto, la participación de las mujeres indígenas portadoras de la vestimenta propia en los levantamientos de la década, constituye un factor determinante para el desarrollo de estos eventos. Participación que estuvo marcada, en primer lugar, por la estrategia de que sean las mujeres quienes abran las marchas de entrada a las ciudades; en segundo término, por la visibilización de la etnia en la zona urbana, a través de la indumentaria - portada principalmente por estas mujeres-; tercero, por la ocupación del espacio público, al permanecer por varios días consecutivos en cada uno de los levantamientos, tal como se detalla en los párrafos siguientes.

En primer lugar, las mujeres indígenas - principalmente las mamas-, portadoras de la vestimenta propia, fueron quienes adelantaban las marchas, enfrentándose a policías y militares (De la Torre, 2010; Medina, 2019), para abrir paso a sus esposos, hijos y demás compañeros de lucha.

Estas mujeres, dedicadas al cuidado de los hijos, del campo y de los animales en sus comunidades - situadas en zonas rurales-, para estos eventos "madrugaban con la importancia de llevar con kukawi ${ }^{7}$, porque pobreza y llevaban hasta la ilusión" (Entrevista con TJLL, Chibuleo San Francisco, diciembre de 2016). Las marchas, que iniciaban en las comunidades, implicaron largas caminatas, como lo indica una informante clave que estuvo presente, "bajamos a pie y subimos a pie, ajá" (Entrevista con MLL, Chibuleo San Francisco, noviembre de 2016).

Las chibuleo, para trasladarse de sus comunidades a las ciudades, acudieron "bien elegantes, bien vestiditas" (Entrevista con TJJLL, Chibuleo San Francisco, abril de 2016), portando la indumentaria chibuleo que poseían en mejor estado - la más nueva-, como lo sostiene uno de los taytas en referencia a los levantamientos. El tayta Juan José describe la indumentaria portada por las mujeres de la década ${ }^{8}$, similar — según indica—, a la que en ese momento viste su esposa. Empieza su descripción por los accesorios: el sombrero blanco; el cabello con el corte marga accha; las orejeras, "un adorno elegante que es de puro coral" (Entrevista con TJJLL, Chibuleo San Francisco, abril de 2016), y las wallkas, que rodean el cuello, hechas también de este material. Continúa su descripción con las prendas: el rebozo, también denominado pachallina; la camisa, con bordados que refieren, en su forma y color, a las flores de las papas o a las flores del campo que, según indica, "es como tener algo, adorno en el cuerpo, adornadito" (Entrevista con TJJLL, Chibuleo San Francisco, abril de 2016). 
El chumbi, o faja - que si bien en el momento de la descripción es una prenda en la que solo se observan decoraciones con formas geométricas-, en la década de los 90-, según este tayta, tenía figuras "de sapito, de venadito, de burrito, de gallito, de gallinita, tenían así tenían estas figuritas, pero ahora ya no tejen, es difícil de hacer eso. Tonce, esas figuras, significa que la mujer también tiene derecho a amar al animalito, es inseparable [de] los animales" (Entrevista con TJJLL, Chibuleo San Francisco, abril de 2016). Esta prenda no solo se usa como adorno "sino para ajustar fuerte para que cargar la hierba, [la mujer] tiene que cargar la hierba, tiene que cargar quintales, tonce eso esa faja sostiene que no se resbale la carga y que tiene fuerza, tiene fuerza va... aguanta la cadera, aguanta el cuerpo por eso es medio cuerpo" (Entrevista con TJJLL, Chibuleo San Francisco, abril de 2016). Además, el chumbi, o los chumbis, tienen también la función de sujetar los anacos al cuerpo. Por último, el anaco, una prenda envolvente que se coloca desde la cintura hasta cubrir las rodillas, es la "Pachamama nuestra madre tierra [...] 4 [anacos] de 3 metros se envolvían, se hacían anaco [...] Por algunas decían que hacían hasta 6, que son redondasas así” (Entrevista con TJJLL, Chibuleo San Francisco, abril de 2016). Y esto lo corrobora TJLL: "Tres a cuatro anacos según el porte de las mujeres tres a cuatro verás así de largo y se envolvía aquí para hacer unos unciditos" (Entrevista con TJLL, Chibuleo San Francisco, diciembre de 2016). La cantidad de anacos portados en esta época, junto con el resto de las prendas usadas, da cuenta, en términos de Saltzman (2004), de una silueta volumétrica.

$\mathrm{Al}$ inicio de cada uno de los levantamientos, en Tungurahua - como en el resto de provincias del país-, los pueblos y comunidades indígenas se comunicaron entre sí para manifestarse en contra de la situación y de las acciones del gobierno, por considerarlas injustas. En sus marchas hacia las ciudades, las columnas fueron reprimidas por fuerzas policiales y militares, que respondían a las autoridades locales y nacionales, según fue expuesto por los chibuleo. Una exposición similar puede hallarse en De la Torre (2010), respecto a las mujeres kichwas ecuatorianas, que se enfrentaban a las fuerzas del orden; suceso registrado por la autora como "un hecho político sin precedentes en la historia del país" ( p. 13). En este punto, la intervención de las mujeres constituyó un acto inédito, en tanto se convierten en la estrategia indígena de entrada a las ciudades:

... nuestra estrategia era que adelante las mujeres, inmediatamente cuando comunicamos por parlante decimos: por favor pasen adelante las mujeres porque vienen los policías, tonces ¡ahí sí! Cuando las mujeres pasaron adelante más o menos unas 500 mujeres y les pa... quisieron impedir que no entremos a la ciudad porque era una tomontonera”. (Entrevista con TJJLL, Chibuleo San Francisco, abril de 2016)

Las mujeres indígenas, identificadas por su vestimenta propia, enfrentaron a los policías y militares del ejército, derribando los cercos para pasar a la ciudad. La fuerza que proporciona a las mujeres el estar fajadas con el chumbi $i^{9}$ - que les permite soportar la carga de los productos agrícolas en las comunidades-, ahora es utilizada para empujar a las fuerzas del orden en su entrada a las ciudades. 
En esto radica la importancia de la participación de las mujeres en los levantamientos, hecho que explica una informante al indicar que desde el año 1990:

... siempre las mujeres éramos primero, los hombres eran atrás para que no le repriman o cojan [...] porque a las mujeres los policías no nos maltrataban mucho, en cambio a los hombres les maltrataban, les pegaban, les llevaban presos. Tonces ellos eran más atrás, las mujeres éramos primeras, esa era la táctica de nosotros, entonces siempre íbamos las mujeres primero. (Entrevista a MLL, Chibuleo San Francisco, noviembre de 2016)

Las acciones de las mujeres chibuleo en Tungurahua, en el momento de la entrada de la etnia a la ciudad de Ambato - principalmente de las mamas que encabezaban las marchas-, convierte su accionar en un elemento clave, no solo a partir de su fuerza física -empujando y derribando a policías y militares-, sino como estrategia identitaria, que visibiliza a la etnia a partir del artefacto vestimentario portado.

En efecto, la visibilización que adquiere la etnia se debe, en gran parte, a las mujeres portadoras de vestimenta propia. Son ellas quienes de manera más consistente han mantenido su indumentaria, no solo durante los levantamientos de la década de 1990, sino hasta la actualidad, prácticamente con la misma tipología en el caso de las mamas chibuleo. Esto constituye una diferencia respecto de una parte de la población masculina, que adoptó una vestimenta considerada mestiza, hecho que, según Bonfil Batalla (1991), se explica como un proceso de resistencia, dentro de lo que denomina la dinámica cultural interétnica. $\mathrm{Al}$ respecto, la informante MLL menciona que durante los levantamientos:

... habían varones que [...] más que todo los varones se vistieron ya de mestizos [...] en la ciudad en el primer levantamiento había muchísima gente de la ciudad que nos apoyaron bastante ¿no? En esa temporada cuando bajaron de las comunidades a las ciudades, no tenían almuerzo, los señores de la ciudad dieron almuerzo a la gente indígena, dieron agua, dieron fruta... las señoras del mercado principalmente, tonces ayudaron a hacer comida todo eso. Tonces a los chicos que estaban vestidos de mestizos no les querían dar pues. No les quería dar a ellos ¡no! a ellos ¡no! ¡dijo no! esto es... son solo para indígenas. Ellos [los hombres chibuleo vestidos de mestizos] también decían: nooo, nosotros también somos indígenas. Decían no porque usted no está vestido de indígena. Tonces las mujeres siempre hemos mantenido nosotros no hemos cambiado. (Entrevista a MLL, Chibuleo San Francisco, noviembre de 2016) ${ }^{10}$

Este hecho ejemplifica la importancia de vestir acorde a la pertenencia étnica para ser identificados e incluso recibir apoyo de los no indígenas durante los levantamientos. Al respecto esta misma informante menciona "hay unas personas que dicen yo si llevo mi identidad en mi alma ¡sí! podrá llevar su identidad en el alma pero no se le reconoce, no se le ve ¿no cierto?” (Entrevista con MLL, Chibuleo San Francisco, noviembre de 2016). De 
aquí en adelante, inicia un proceso de revitalización indumentaria, no solo por parte de las mujeres sino de la población indígena en general, que internaliza (Roach y Eicher, 1992) el uso del vestido étnico, en tanto aporta al reconocimiento del grupo.

Esto corrobora el hecho de que la vestimenta funge como primer medio de comunicación -incluso antes que el verbal-, por ser la indumentaria el elemento más visible (Roach y Eicher, 1992), a través del cual se diferencia e identifica a una persona como perteneciente a un grupo determinado. En el caso de los chibuleo, la indumentaria también se convierte en una estrategia de reconocimiento como rasgo diacrítico (Barth, 1976), que los identifica al interior de la etnia y los diferencia de los no indígenas.

En estos levantamientos las mujeres también "estuvieron gritando [...] ese papel era muy importante" (Entrevista con TJLL, Chibuleo San Francisco, diciembre de 2016). Esta acotación pone de manifiesto el activo papel militante de las mujeres, no solo en la entrada a las ciudades, sino también en su multitudinaria participación verbal durante los levantamientos. Los hombres elevaban su voz de protesta contra las injusticias a la que había sido sometida la etnia; las mujeres - con sus gritos al unísono del resto de la población indígena, en apoyo a las intervenciones de sus representantes-, aportaban a la identificación del grupo. Estos actos ponen en evidencia la representatividad del grupo, tanto en número, como en capacidad de organización y unidad para demandar sus derechos colectivos.

Esta visibilización implicó sacrificios, al ir las mujeres acompañadas de sus hijos. Las madres llevan a los niños y niñas más grandes caminando a su lado; los de temprana edad son cargados, y otras avanzan incluso embarazadas. Una de ellas recuerda acerca de los levantamientos que, "yo para eso yo ya tuve mi hijo tenía 3, 4 meses algo así y casi murió entre las bombas, una señora me ayudó a coger y puso en el humo de donde que estaban quemando ahí puso para que pueda respirar mi bebe, casi le maté" (Entrevista con MLL, Chibuleo San Francisco, noviembre de 2016).

Las mujeres, si bien eran reprimidas en menor grado - a pesar de abrir paso a la población-, no eran inmunes a los atropellos: "a las mujeres los policías no nos maltrataban mucho" (Entrevista con MLL, Chibuleo San Francisco, noviembre de 2016). Otro ejemplo de las dinámicas al interior del grupo de mujeres es dada por la misma informante, respecto a su hijo, que contaba con menos de seis meses de edad: "yo cargando con bayeta [rebozo] había mis vecinas decían presta te ayudo a cargar así y me ayudaban a llevar [...] caminando desde aquí y subíamos caminando también con el bebe" (Entrevista con MLL, Chibuleo San Francisco, noviembre de 2016). En este sentido se expone al rebozo —este término es más apropiado que bayeta tanto por la referencia temporal como por sus características dimensionales - como prótesis que facilita, a las mujeres, el traslado de los niños.

Como tercer punto, que también visibiliza a la etnia, es la intervención de las mujeres en la ocupación del espacio público, tanto como estrategia identitaria en el lugar, como para la permanencia de la etnia en la ciudad. La indumentaria de las mujeres, como artefacto de diseño, se convierte en una prótesis que amplía sus capacidades, no solo en su marcha a las ciudades, sino también en la permanencia en la urbe, es decir, durante todo el proceso. Durante estos eventos las mujeres proveen alimento a su comunidad. No solamente los alimentos que habían llevado preparados, denominados kukawi - como lo expone TJJLL "unas cargadas shigritas con kukawi" (Entrevista con TJJLL, Chibuleo San Francisco, abril de 2016) - , sino también elaboraban comida en el lugar, con los implementos de cocina 
y productos que transportaban desde sus hogares en las zonas rurales. Así lo registra uno de los diarios de circulación local: "es indiscutible la organización de las comunidades indígenas. Los participantes en el paro o minga, en el lugar en que se encontraban, eran atendidos con la alimentación respectiva" (El Heraldo, 13 de octubre de 1992).

Este hecho da cuenta de la ocupación del espacio público, hecha por los indígenas, en calles y veredas de la urbe, para resolver sus necesidades de alimentación; esto es a la vez determinante para asegurar su permanencia a lo largo de varios días de movilización. Esta ocupación es también registrada por los diarios, al indicar puntualmente que previo al ingreso del grupo étnico al estadio Bellavista —en Ambato—, para sostener diálogos con las autoridades "se sentaron para ingerir algún refresco o cierto fiambre" (El Heraldo, 6 de junio de 1990).

A partir de lo expuesto en los párrafos anteriores, se sostiene aquí la función de la indumentaria como prótesis. Las shigras — bolsos_-, son utilizadas por las mujeres para transportar alimentos preparados desde sus comunidades; los rebozos se usan para envolver los implementos de cocina y productos alimenticios, que deben ser cargados sobre sus espaldas hasta llegar a los espacios públicos de la urbe, en donde se utilizan para preparar más comida.

La ocupación del espacio también implicó la realización de labores manuales por parte de las mujeres, para soportar las extensas jornadas de paralización de las ciudades, como lo expresa uno de los taytas: "de repente cuando toca sentar en levantamiento... ahí van llevando a hacer suéter [saco] a hacer shigra, a tejer alguna cosa" (Entrevista con TJJLL, Chibuleo San Francisco, abril de 2016). Es decir, tanto para la ingesta de alimentos como para las actividades de tejido y bordado, las mujeres toman asiento en el suelo, lo que expone la funcionalidad de portar varios anacos, en tanto las numerosas capas de tejido - que conforman las prendas de envoltura-, permiten soportar el contacto del cuerpo con la superficie dura y áspera del pavimento en las calles y el cemento de las veredas (ver figura 1).

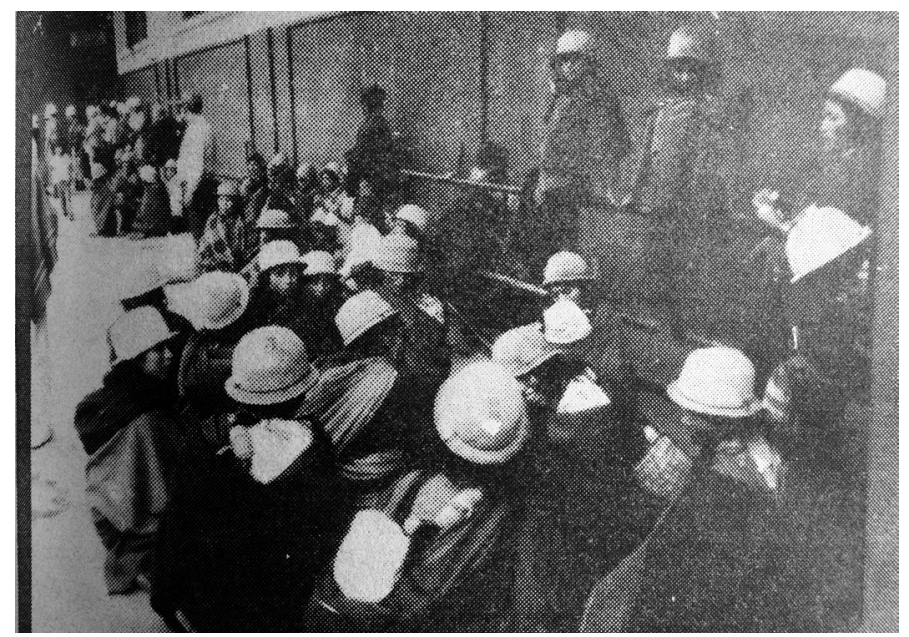

Figura 1. Mujeres con vestimenta propia, sentadas durante el levantamiento de 1990. Fuente: El Heraldo (Ambato, 1990). 
La indumentaria, como elemento de protección corporal, es indispensable en las marchas de entrada a la ciudad, las caminatas hacia los lugares de diálogo con las autoridades y las marchas pacíficas para el cierre de los levantamientos. Destaca, en este punto, el uso del sombrero blanco, que por sus características de color y dureza estructural, cumple un papel determinante ante las inclemencias climáticas.

Las mujeres, que se constituyen como ejes estratégicos al ser portadoras de la vestimenta propia durante los levantamientos, son registradas en múltiples ocasiones por los diarios, incluyendo imágenes que dan cuenta de lo antedicho (ver figuras 1 y 2). Esto también puede constatarse en lo expuesto en 1990 por el diario El Heraldo, cuando refiere a la culminación de la movilización de ese año con el titular "Seis días duró el levantamiento indígena", acompañado de una fotografía que dice: "La mujer también estuvo presente en la dura jornada llevada a cabo por la población indígena de Tungurahua" (El Heraldo, 8 de junio de 1990) (ver figura 2). Si bien la mención del diario indica que las mujeres no fueron las únicas presentes en el levantamiento - como ya ha sido expuesto, los hombres fueron la voz de los levantamientos-, la imagen que muestra el medio de comunicación refiere solamente a mujeres, lo que da cuenta de su destacado rol en este acontecimiento.

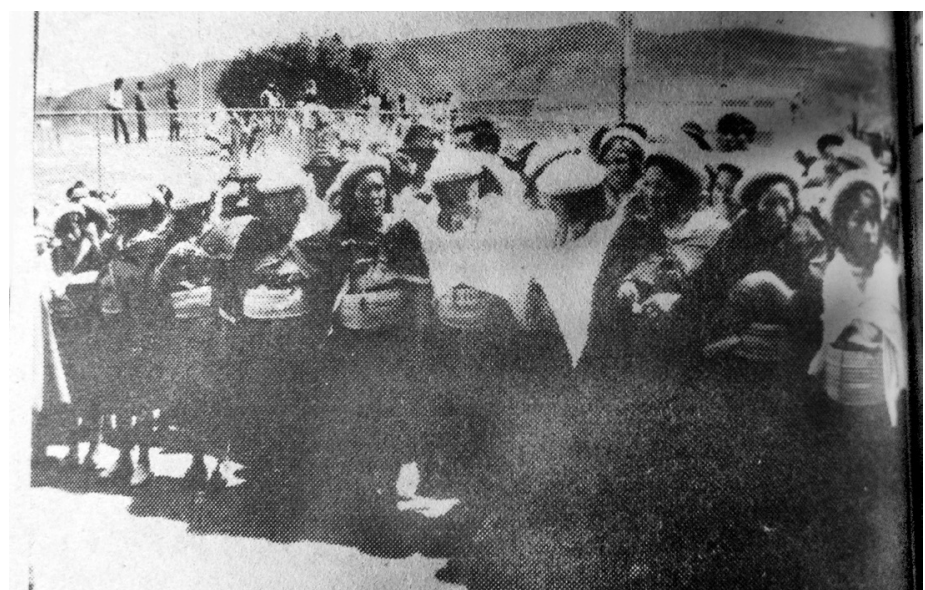

Figura 2. Mujeres chibuleo con vestimenta propia, presentes en el levantamiento de 1990. Fuente: El Heraldo (Ambato, 1990).

En 1992, la actuación de las mujeres se repite y es nuevamente reportada por los medios: "Tuvo destacada actuación en la medida de hecho la mujer indígena, inclusive con sus hijos en sus espaldas" (El Heraldo, 13 de octubre de 1992). En este caso el diario hace mención a las mujeres no solo en su participación militante durante el levantamiento, sino también en su rol de madres, al destacar que acuden a los eventos cargando a sus hijos. 
Los rebozos - con sus puntas anudadas sobre el pecho de las mujeres-, envuelven el cuerpo de los niños cargados en las espaldas indígenas, cumpliendo la función de prótesis. La participación de hombres y mujeres culminó en cada uno de los eventos con una marcha pacífica, hecho que en 1990 fue registrado por la prensa con el titular "Terminó el levantamiento indígena de Tungurahua" (El Heraldo, 8 de junio de 1990). En esa publicación se expone que en esta provincia - luego de conocer la resolución de la CONAIE-, también se decide levantar la medida respecto de la paralización de la ciudad, con una multitudinaria manifestación pacífica que inicia en el estadio de Bellavista y recorre las calles de la ciudad hasta llegar a la gobernación. En este último lugar existe un diálogo entre los líderes indígenas y el gobernador - que accede a reunirse al constatar la masiva presencia indígena que inunda las calles-, con la intervención también de otras autoridades de la provincia y autoridades eclesiásticas, que culmina con la firma de un Acta de Compromiso. La forma en que terminó este levantamiento, marcó un precedente en el modo de cierre de los siguientes levantamientos.

Las mujeres visibilizan a la etnia ante la mirada no indígena, y también al interior del grupo indígena. Las mujeres indígenas son reconocidas desde lo humano, en su rol de madres, esposas, hijas, y al mismo tiempo, activistas que reclaman los derechos de la etnia, demandando justicia para sus familias y su comunidad. Después de siglos de represión y sumisión, los cuerpos sociales de las mujeres, ahora políticos, demandan no solo la reivindicación de los derechos de la etnia; también demandan respeto como mujeres. En adelante, se posicionan de tal forma que son consideradas para ocupar puestos de dirigencia comunitaria, e incluso de política provincial y nacional - aunque esto último no ocurre en el caso de las chibuleo-, y con mayor frecuencia, cargos públicos y privados en la urbe, lo que da cuenta de los nuevos roles que asumen las mujeres en contextos distintos a su trabajo rural y el cuidado de sus familias.

La indumentaria, como diacrítico de identidad, marca la presencia étnica durante los levantamientos. Su reconocimiento en la Carta Magna se plasma por primera vez en 1998, siendo esta una demanda que había formado parte de los reclamos durante los levantamientos desde inicios de la década de 1990. Así lo expresa la informante: "cuando decimos que debemos ser reconocidos... en la Constitución entonces no fue solo simplemente en nuestro idioma, sino todo lo que es nuestra identidad cultural todo, en sus mitos, sus ritos, todo y todas esas cosas nuestras fiestas nuestras tradiciones, nuestro idioma todo en general" (Entrevista con MLL, Chibuleo San Francisco, noviembre de 2016). En este sentido, la indumentaria forma parte de lo que la informante menciona como 'nuestra identidad cultural', que en la Constitución se reconoce como el uso de la vestimenta con la que se identifiquen los pueblos indígenas, siendo esto parte de los derechos reivindicados.

La indumentaria se convierte en el vehículo de identidad de las minorías étnicas que demandan y reivindican sus derechos; indumentaria con particularidades enfocadas para el trabajo en el campo, pero que se adapta y permite la permanencia de sus portadores en la urbe. Es en este sentido que la vestimenta muestra su categoría artefactual con inscripciones políticas, que posiciona a los indígenas como un actor de relevancia en el escenario político del Ecuador. 


\section{El artefacto indumentario, entre la política y el diseño}

La indumentaria, como artefacto de diseño, materializa los elementos culturales (Broncano, 2009) de un grupo y permite la integración de los sujetos que la portan a la cultura cotidiana (Bonsiepe, 1998) en contextos determinados. En este sentido, en el artefacto vestimentario indígena confluyen las características étnicas en general y se ponen en evidencia las prácticas y costumbres de vestir de cada uno de los pueblos. Si bien este artefacto permite la integración de sus portadores al interior de sus comunidades - en una etnicidad privada-, en las protestas de la década de 1990 este artefacto es una muestra de lo diferente ante "los otros" (Abramoff, 2001; Ulloa, 2005). Por un lado, irrumpe en la cotidianidad de la urbe, y por el otro se adapta y permite la permanencia de los usuarios en las ciudades, exponiendo públicamente su etnicidad.

El tránsito del cuerpo biológico al cuerpo cultural en el momento de uso (Fernández, 2018) es otro de los aportes de la indumentaria como artefacto de diseño; cuando este cuerpo cultural vestido se hace público - a través de sus reclamos y demandas en los levantamientos-, se transforma en un cuerpo político, en el que la vestimenta es su máxima representante. Esta vestimenta, en tanto artefacto, es la suma de prótesis e interfaces ${ }^{11}$, que interactúan sobre el cuerpo como soporte (Saltzman, 2004), en el momento de uso y en un contexto determinado.

La interfaz del artefacto vestimentario de las mujeres, durante los levantamientos indígenas, "es un espacio de interacción del cuerpo, la vestimenta y el contexto en el momento del uso" (Medina, 2019, p. 60). Asimismo, comunica la intencionalidad de la etnia de visibilizarse dentro de la sociedad ecuatoriana, como humanos que comparten un mismo espacio con las etnias no indígenas, es decir, en su integración a la vida cotidiana. Con ello, se logra satisfacer las necesidades de la etnia respecto de acceder a sus derechos como sujetos sociales que viven y comparten un mismo espacio - el Estado-Nación ecuatoriano-, y la consolidación de una identidad resignificada en el marco del respeto - como se refieren a ello los informantes-, a partir de la reivindicación y reconocimiento de estos derechos.

La vestimenta indígena, como interfaz del artefacto de diseño, es la estrategia identitaria que da cuenta de la representatividad de la etnia en número, aporta en el reconocimiento del grupo - que alcanza su participación en espacios políticos-, y visibiliza a los indígenas - particularmente a las mujeres-, tanto al interior de la etnia como frente a los no indígenas, como sujetos sociales y activistas políticos.

En tanto prótesis, la indumentaria de las mujeres se incorpora al cuerpo (Broncano, 2009) para la integración de este último a la vida social en las comunidades, y a la vida pública en la urbe frente a los no indígenas.

Los numerosos anacos, chumbis y rebozos - principalmente-, en combinación con la lishta y la camisa, por una parte dan cuenta de la silueta volumétrica (Saltzman, 2004) de las mujeres al aumentar el volumen corporal en sentido horizontal. Por la otra, amplían las capacidades de sus cuerpos para trasladarse desde la zona rural a la urbana, y para permanecer en este último lugar por varios días, paralizando las ciudades. En efecto, la indumentaria portada por las mujeres indígenas tuvo que adaptarse a las condiciones que 
demandaba su movilización en estos eventos; a continuación se describe la manera en que las mujeres adaptan el uso de cada una estas prendas.

En primer lugar, los chumbis, que dan firmeza a la cadera para soportar la carga de los productos agrícolas en el trabajo rural, aumentan la fuerza física de las mujeres en las marchas, que derriban así a policías y militares en su entrada a las ciudades.

Los rebozos, que son habitualmente utilizados para envolver los productos agrícolas y transportarlos dentro de la comunidad, permiten en estos eventos que las mujeres carguen a los niños, en su marcha desde sus pueblos a la urbe; así como también estos indumentos sirven para transportar provisiones e implementos de cocina, lo que les posibilita preparar alimentos fuera de sus hogares. Los chumbis, envueltos sobre los múltiples anacos, aparte del aporte descripto, también sirven de soporte a la cadera para que el cuerpo resista estas cargas.

Los anacos, en varias capas superpuestas, permiten acomodar los cuerpos de las mujeres sobre la dura superficie del pavimento y las veredas del espacio público, mientras se sientan interminables horas en las jornadas de paralización de la ciudad.

Los accesorios también cumplen con su función de prótesis. La shigra, utilizada como contenedor, permite llevar el kukawi, —es decir, alimentos listos para ser ingeridos-, que se comparte entre la población. El sombrero cubre la cabeza de las múltiples condiciones climáticas - que transitan abruptamente entre la lluvia y el sol-, además de proteger a esta parte del cuerpo contra las agresiones de las fuerzas de seguridad, que intentan reprimir a la población con elementos que atentan contra su integridad física.

Lo expuesto da cuenta de la indumentaria como prótesis material y, al mismo tiempo, cultural. Por una parte, la indumentaria, en su conjunto, cumple la función primaria (Fernández, 2015, 2016) de proteger el cuerpo y amplía sus capacidades de adaptación a nuevos entornos. Por la otra, este artefacto vestimentario se porta en un contexto político y social específico, que es la trama en la que se teje la vestimenta.

En definitiva, la visibilización de las mujeres a través de su vestimenta y su militancia durante los levantamientos, fortalece y reafirma su identidad como indígena y como chibuleo, lo que da cuenta de la categoría artefactual de este objeto de diseño. La indumentaria, como interfaz, comunica la lucha indígena, la demanda de justicia del grupo y la búsqueda del respeto chibuleo. Asimismo, las prestaciones de la indumentaria - al ampliar las capacidades de los cuerpos de las mujeres indígenas-, son las prótesis que permiten el desarrollo de los eventos. En este sentido, la indumentaria, como artefacto de diseño, aporta a la construcción de la identidad y la memoria colectiva de la etnia en el país, a tal punto que se convierte en la impronta política inscripta sobre los cuerpos de las mujeres que la portan.

Con el presente artículo, se continúa saldando el hiato conceptual entre los estudios de Diseño de Indumentaria y los grupos étnicos, tal como lo explora Medina (2019) en su tesis doctoral. Además, aporta al reto propuesto por Roach y Eicher (1992) respecto de ahondar en una teoría del vestido ligada a la comunicación de la identidad. Este documento constituye un aporte a la colectividad científica, principalmente de las Ciencias Sociales, particularmente para quienes desarrollan investigaciones sobre Diseño, o acerca de la reconstrucción de los procesos de reconocimiento identitario de las minorías étnicas. 
Además, es un soporte para la realización de proyectos en el marco de un diseño ético, que inicia con el reconocimiento de problemas especiales para avanzar a su adecuación (Mitcham, 1995). Este diseño, concebido con el fin de desarrollar objetos cotidianos desde la realidad de los actores, asume un compromiso con la alteridad y reconoce la producción objetual con trasfondo cultural (Arbeláez, 2015). En este sentido, la comprensión de la realidad de las mujeres chibuleo en el contexto político en el que despunta su participación, constituye la base sobre la que se asienta el diseño indumentario chibuleo de la década de 1990, y en adelante la producción artefactual de las nuevas generaciones de mujeres que mantienen rasgos indumentarios indígenas como diacríticos de su identidad. Lejos de concluir la temática, la indumentaria indígena - como artefacto de diseño y lugar de las inscripciones políticas de la etnia-, que hacen parte de su identidad en determinadas épocas y contextos, constituye un punto de partida para desarrollar investigaciones similares de otros grupos étnicos, o al interior del mismo pero en épocas distintas. Asimismo, abre el diálogo para continuar explorando las potencialidades de la indumentaria como artefacto de diseño, que aporte a la institucionalidad del Diseño, más allá de los estudios de Occidente.

\section{Notas:}

1. Eicher (2000) sostiene que el vestido 'étnico' surge de la comparación del vestido de los miembros de un grupo con el de otros. Término abordado también por Hansen (2004) en este mismo sentido.

Cabe aclarar que el término 'vestido' lo asumo desde Eicher y Roach (1992), como el conjunto de modificaciones del cuerpo y/o complementos portados por una persona. Para el caso de las mujeres chibuleo, en adelante me referiré como vestimenta o indumentaria en tanto complementos que se añaden al cuerpo, por ser éstos términos los que abordan tanto a las prendas como a los accesorios motivos de análisis.

2. Este levantamiento fue precedido por la conformación de la Confederación de las Nacionalidades Indígenas del Ecuador (CONAIE) en 1986; por un proyecto de ley propuesto por la CONAIE en 1988 - que no fue aceptado-, y la firma del Convenio 169 de la Organización Internacional del Trabajo (OIT).

3. Los chibuleo residen en la parroquia rural de Juan Benigno Vela del cantón Ambato, provincia de Tungurahua.

4. Según Medina (2019) "la 'vestimenta propia' es una categoría nativa chibuleo, utilizada para referirse al empleo de la indumentaria - sin mayores modificaciones- que se ha transmitido de generación en generación y que identifica a quienes pertenecen a este pueblo" (p. 22)

5. Los 'taytas' son líderes indígenas chibuleo, que dirigieron los levantamientos principalmente de la década de 1990 y que en la actualidad sobrepasan los 70 años de edad. La denominación de 'taytas', al igual que la de 'mamas' responde a categorías nativas identificadas por Medina (2019) y refiere a "indígenas que aún portan lo que en términos chibu- 
leo puede considerarse vestimenta indígena” (p. 40). Este último término es un sinónimo de vestimenta propia.

6. Las mamas "son mujeres entre 70 y 80 años que participaron en estos eventos [...] $\mathrm{Al}$ interior de este grupo se identifica otra categoría de mujeres entre 45 y 55 años reconocidas como mamas por la comunidad, sea por su forma de vida similar a las mujeres de la primera categoría, o por su contribución al desarrollo del pueblo desde cargos comunitarios" (Medina, 2019, p. 23). Este último grupo también tuvo participación en los levantamientos de la década de 1990.

7. Palabra kichwa, usada habitualmente para referirse a un fiambre o una colación.

8. Los estudios de Medina (2019) hacen un abordaje respecto a la indumentaria de esta época que corresponde a la tipología de vestimenta propia portada por el grupo de mujeres, denominada por los chibuleo como las mamas. Asimismo, las descripciones de Rowe $(1998,2011)$ basadas en su etnografía desarrollada en 1988, constituyen un acercamiento a la indumentaria, previa al inicio de los levantamientos de 1990.

9. Medina (2020), hace un abordaje respecto a las funciones del chumbi que amplía lo expuesto.

10. A pesar de la aseveración de la informante respecto a que no se ha cambiado la indumentaria, los estudios de Medina (2019), a partir de su etnografía, ponen en evidencia las diversas tipologías vestimentarias que se derivan de la vestimenta propia, y se transforman en los arquetipos vestimentarios de mujeres que en el presente trabajan en instituciones públicas o privadas, en los ámbitos educativos y financieros, con las denominaciones de 'vestimenta de la cultura' en el primer caso, y 'uniforme propio' en el segundo.

11. Se asume para el presente artículo a la indumentaria como prótesis, que amplía las capacidades del cuerpo al complementarlo (Fernández, 2015), en tanto en el momento de uso los objetos - sean vestimentarios o de diferente índole- solventan las necesidades del cuerpo (Broncano, 2009; Maldonado, 1998; Manzini, 1996).

Asimismo, cuando es analizada en términos de interfaz, en tanto vía de interacción entre el objeto y el cuerpo a partir de la experiencia de uso en un contexto, se sigue lo sostenido por Fernández $(2015,2016)$ y lo expuesto por teóricos destacados en el diseño, como Bonsiepe (1998) y Krippendorff (2006).

\section{Lista de referencias bibliográficas}

Abramoff, E. (2001). Etnocidio. Genocidio. Identidad de los Pueblos Indígenas. En Garreta, M. J.; Bellelli, C.; Bonaparte, P.; Abramoff, E.; Acosta, A.; Cañas, L.; Scheinsohn, V. La trama cultural. Textos de antropología y arqueología (2da. ed., pp. 155-163). Buenos Aires: Caligraf.

Almeida, I.; Almeida, J.; Bustamante, S.; Espinosa, S. H; Frank, E.; Ibarra, H.; Rutz, L. (1992). INDIOS. Una reflexión sobre el levantamiento indígena de 1990 (2 ed.). Quito: Agya-Yala. Almeida, I., Arrobo, N. y Ojeda, L. (2005). Autonomía Indígena frente al Estado nación y a la globalización neoliberal. Quito: Abya Yala. 
Arbeláez, E. (2015). El diseño como disciplina eminentemente práctica, transformativa y comunicativa. Iconofacto, 11(17), 74-80.

Barth, F. (1976). Los grupos étnicos y sus fronteras. La organización social de las diferencias culturales. México: Fondo de cultura económica.

Benítez, L. y Garcés, A. (2014). Culturas ecuatorianas ayer y hoy (2 ed.). Quito: Abya-Yala. Bonfil Batalla, G. (1991). La teoría del control cultural en el estudio de procesos étnicos. Estudios sobre las Culturas Contemporáneas, 4(12), 165-204.

Bonsiepe, G. (1998). Del objeto a la interfase: mutaciones del diseño. Buenos Aires: Infinito. Broncano, F. (2009). La melancolía del ciborg. Barcelona: Herder.

Caluña, N., Tisalema, M., y Caluña, T. (2008). Los chibuleos: origen, identidad, desarrollo y justicia de un pueblo indígena en los andes ecuatorianos. Quito: Artes gráficas Silva.

Cruz, A. (2010). Pueblos originarios en América: guía introductoria de su situación. Pamplona: Aldea.

De la Cadena, M. (1991). "Las mujeres son mas indias": Etnicidad y género en una comunidad del Cusco. Revista Andina. estudios y debates, 17(1), 7-47.

De la Torre Amaguaña, L. M. (2010). ¿Qué significa ser mujer indígena en la contemporaneidad? MESTER, 39(1), 1-25. Disponible en: http://escholarship.org/uc/item/9m93c0fs

"Ecos del levantamiento indígena" (13 de octubre de 1992). Diario El Heraldo. Ambato.

Eicher, J. (2000). The anthropology of dress. The Journal of the Costume Society of America, 27(1), 59-70.

Eicher, J., y Roach, M. (1992). Definition and Classification of Dress. Implications for Analysis of Gender Roles. En J. Eicher, y R. Barnes, Dress and Gender: Making and Meaning in Cultural Contexts. (pp. 8-28). Berg Publishers.

Fernández, C. (2015). La profundidad de la apariencia. Contribuciones a una teoría del diseño de vestuario. Medellín: UPB.

Fernández, C. (2016). El vestido como artefacto del diseño. Contribuciones para su estudio y reflexión al interior del pensamiento de diseño (Tesis doctoral inédita). Manizales: Universidad de Caldas.

Fernández, C. (2018). El vestido como artefacto del diseño: Contribuciones para un estudio y reflexión al interior del pensamiento del diseño. Encuentros, 16 (2), 79-91.

"Gobernador anhela que situación se normalice" (6 de junio de 1990). Diario El Heraldo. Ambato.

Hansen, K. (2004). The world in dress: Anthropological perspectives on clothing, fashion, and culture. Annual Review Anthropology, 33, 369-392.

Iturralde, D. (2000). Lucha indígena y reforma neoliberal: el movimiento indígena como actor político. Íconos-Revista de Ciencias Sociales(9), 22-30.

Jackson, J. (1995). Culture, genuine and spurious: the politics of Indianness in the Del Vaupés, Colombia. American Ethnologist. The journal of the American Ethnological Society, 22(1), 3-27.

Krippendorff, K. (2006). The semantic Turn, a New Foundation for Design. Boca Ratón: Taylor y Francis.

Maldonado, G. (2012). Matices y texturas de la identidad cultural étnica en contextos urbanos. En el caso de los kichwas de Chimborazo. En Kigman, E. San Roque: indígenas urbanos, seguridad y patrimonio. Quito: FLACSO, HEIFER . 
Manzini, E. (1996). Artefactos. Hacia una nueva ecología del ambiente artificial. Madrid: Celeste Ediciones y Experimenta Ediciones de Diseño.

Medina, A. (2019). Indumentaria e identidad: análisis de la vestimenta de la mujer indígena desde el diseño. El caso del pueblo chibuleo (Tungurahua, Ecuador 1990-2016) (Tesis doctoral inédita). Buenos Aires: Universidad de Palermo, Facultad de Diseño y Comunicación.

Medina, Aylen (2020). El chumbi andino. Reflexiones en torno a la potencialidad de su estudio desde las funciones del vestido. Revista inclusiones, 7 (número especial), 96-116.

Mitcham, C. (1995). Ethics into Design. En Buchanan, R. y Margolin, V. (Eds). Discovering Design. Explorations in Design Studies (pp. 173-189). Chicago: The University of Chicago Press.

Pequeño, A. (2007). Imágenes en disputa. Representaciones de mujeres indígenas ecuatorianas. Quito: Abya-Yala; FLACSO, sede Ecuador .

Porras, A. (2005). Tiempo de indios. La construcción de la identidad política colectiva del movimiento indio ecuatoriano (Las movilizaciones de 1990, 1992 y 1997). Quito: Abya-Yala.

Prieto, M.; Cuminao, C.; Flores, A.; Maldonado, G. y Pequeño, A. (2005). Las mujeres indígenas y la búsqueda del respeto. En Prieto, M. Mujeres ecuatorianas: entre las crisis y las oportunidades 1990-2004 (pp. 155-194). Quito: CONAMU, FLACSO Sede Ecuador, UNIFEM, UNFPA.

Roach, M., y Eicher, J. (1992). Dress and identity. Clothing and textiles research journal, 10 (4), 1-8.

Rodríguez Maeso, S. (2008). Relaciones de poder e inscripciones identitarias: Mujeres y diferencia cultural indígena en contextos latinoamericanos. Ex aequo (17), 53-70.

Rowe, A. P. (ed.) (1998). Costume and identity in highland Ecuador. Washington DC, Seattle: The Textile Museum, University of Washington Press.

Rowe, A. P. (ed.) (2011). Costume and History in Highland Ecuador. Austin: University of Texas Press.

Saltzman, A. (2004). El Cuerpo Diseñado. Buenos Aires: Paidós.

"Seis días duró el levantamiento indígena" (8 de junio de 1990). Diario El Heraldo. Ambato.

Spadafora, A.; Gómez, M. y Matarrese, M. (2010). Rumbos y laberintos de la política étnica: organizaciones unificadas y faccionalismos indígenas en la provincia de Formosa (pilagá y toba). En Gordillo, G. y Hirsch, S. Movilizaciones indígenas e identidades en disputa en la Argentina (pp. 237-257). Buenos Aires: La Crujía.

Tello, E. (2012). Movimiento Indígena y sistema político en Ecuador. Una relación conflictiva. Quito: Abya Yala.

“Terminó el levantamiento indígena de Tungurahua" (8 de junio de 1990). Diario El Heraldo. Ambato.

Ulloa, A. (2005). Las representaciones sobre los indígenas en los discursos ambientales y de desarrollo sostenible. En Mato, D. Políticas de economía, ambiente y sociedad en tiempos de globalización. (pp. 89-109). Caracas: Facultad de Ciencias Económicas y Sociales.

Wright, S. (1998). The Politicization of 'Culture'. Anthropology Today, 14 (1), 7-15. 


\begin{abstract}
Clothing, as a design artifact worn by indigenous women during the 1990s, has political inscriptions that transform the social body of these women into a political body, which denounces oppression and demands rights. In this sense, clothing is analyzed, on the one hand, as an interface that communicates the fight for the claim of ethnic rights. And, on the other hand, as a prosthesis that expands the capacities of the body to occupy public space, during the indigenous uprisings that occurred in Ecuador in the 1990s.

That era was decisive regarding indigenous representation in Ecuadorian politics; a process that was similar to that occurring in other Latin American countries. The uprisings and the consolidation of the indigenous social movement record the importance of this group in the history of the construction of the Nation-State. The actions taken by this ethnic minority are based on the constitutional recognition of their rights in the 1998 Magna Carta. In this scenario, indigenous women register their presence through clothing, which they wear in both, public and private spheres. Clothing identifies the town where the women belong; it also endows these people with a collective identity that is strengthened in the daily use of the design artifact.

Identity is re-signified in concomitance with clothing. The Chibuleo women's clothed body, which at first highlights their rural work in the community, is transformed into a political body, whose clothing makes women visible in the urban public space, and with this, the existence of this same people in the framework of the fight and demand for rights of indigenous peoples and nationalities in Ecuador. Clothing constitutes the design artifact with a political imprint, which represents the re-signified identity of the people in particular and of ethnic minorities in general.
\end{abstract}

Keywords: Clothing - indigenous woman - identity - politics - design artifact

Resumo: A indumentária, como artefato de design usado por mulheres indígenas durante os anos 90, possui inscrições políticas que transformam o corpo social dessas mulheres em um corpo político, que denuncia opressão e exige direitos. Nesse sentido, o vestuário é analisado aqui, por um lado, como uma interface que comunica a luta pela reivindicação dos direitos do grupo étnico; por outro lado, como uma prótese que expande as capacidades do corpo para ocupar o espaço público, durante as revoltas indígenas ocorridas no Equador na década de 1990.

Essa era foi decisiva em relação à representação indígena na política equatoriana, processo semelhante ao ocorrido em outros países da América Latina. As revoltas e a consolidação do movimento social indígena registram a importância desse grupo na história da construção do Estado-Nação. As ações tomadas por essa minoria étnica baseiam-se no reconhecimento constitucional de seus direitos na Carta Magna de 1998. Nesse cenário, as mulheres indígenas registram sua presença através das roupas que elas usam tanto na esfera pública quanto na privada. A roupa identifica o grupo onde as mulheres pertencem; da mesma forma, confere a elas uma identidade coletiva que é fortalecida no uso diário da indumentária. 
A identidade é ressignificada em concomitância com as roupas. O corpo vestido das mulheres chibuleo, que inicialmente destaca seu trabalho rural na comunidade, é transformado em um corpo político, cujas roupas tornam as mulheres visíveis no espaço público urbano e, com ele, a existência do grupo étnico no âmbito da luta e da demanda pelos direitos dos povos e nacionalidades indígenas no Equador. A indumentária constitui o artefato desenhado com uma intenção política, que representa a identidade ressignificada da população em particular e das minorias étnicas em geral.

Palavras chave: Indumentária - mulher indígena - identidade - política - artefato de design

[Las traducciones de los abstracts fueron supervisadas por el autor de cada artículo] 